\title{
DIDÁTICA NOS ANOS INICIAIS DO ENSINO FUNDAMENTAL: UM ESTUDO SOBRE A DOCÊNCIA DE 11 PROFESSORAS
}

\author{
DIDACTICS IN THE EARLY YEARS OF ELEMENTARY SCHOOL: \\ A STUDY ON TEACHING OF 11 TEACHERS \\ ENSEÑANZA EN LOS PRIMEROS AÑOS DE LA EDUCACIÓN \\ FUNDAMENTAL: UN ESTUDIO SOBRE LA ENSEÑANZA \\ DE 11 PROFESORES
}

\begin{abstract}
Rosineire SiLva De Almeida ${ }^{\mathrm{I}}$
Giseli BARRETO DA CRUZ ${ }^{\mathrm{II}}$

'Universidade Federal do Rio de Janeiro (UFRJ), Rio de Janeiro/RJ - Brasil "Universidade Federal do Rio de Janeiro (UFRJ), Rio de Janeiro/RJ - Brasil
\end{abstract}

RESUmo Este trabalho teve por objetivo analisar aspectos da docência de 11 professoras que são reconhecidas pelos seus pares como referência de prática docente, porque ensinam na perspectiva de "fazer aprender alguma coisa a alguém" em contraposição à ideia de ensino como ato de "professar um saber", conforme distingue Roldão (2007). Teoricamente apoiou-se em Roldão, para abordar a dupla transitividade e a mediação no processo de ensino-aprendizagem, e em Shulman, no que se refere à base de conhecimento profissional docente. Metodologicamente, considerou a técnica da bola de neve, que utiliza cadeias de referências e entrevistas semiestruturadas. Onze professoras de escolas públicas localizadas no Estado do Rio de Janeiro/BR participaram da pesquisa. A análise dos dados foi construída em três eixos: concepções de ensino, saberes mobilizados pelas professoras para ensinar na perspectiva de "fazer aprender alguma coisa a alguém" e estratégias de ensino elaboradas pelas professoras. Os resultados indicam que as professoras concebem o ensino como ato investigativo; as professoras se apresentam como pesquisadoras e criadoras de novas e variadas estratégias para ensinar; o processo pedagógico de mediação das professoras entre o conhecimento e o aluno envolve múltiplos saberes para suprir a necessidade da classe e dos alunos individualmente.

PalaVras-chave: Didática e Docência; Ensino-Aprendizagem; Ensino Fundamental I. 
ABSTRACT Its objective was to investigate the teaching of Elementary School's early years teachers, who work under the perspective of "making someone learn something", opposed to the idea of the teaching as "professing a knowledge" (ROLDÃO, 2007), being recognized as such by their peers as reference of teaching practices. The theoretical referential was composed mainly by two analytical categories: Roldão, in approaching the double transitivity; and Shulman, on what refers to the teaching professional knowledge base. Methodologically, it was considered the snowball technique, which is composed by reference chains and semistructured interviews. Eleven teachers of public schools participated as research subjects. The data analysis was constructed as from three axis: teaching and knowledge conceptions mobilized by the teachers in order to teach on the perspective of "making someone learn something"; didactic strategies elaborated by the teachers. The results indicate that the teachers conceive teaching as an investigative act, that demands various types of knowledge, and also specialized, such as the mobilization of several types of knowledge; the teacher presents himself as a researcher and creator of new and diversified strategies to teach constantly seeking to study and to exchange with their peers and their experiences to accomplish a better work; the study cases analyzed point to a teacher mediation between knowledge and student through a pedagogical process that involves multiple knowledge to suppress class and student's needs individually.

Keywords: Didactics and Teaching; Teaching-Learning; Early Years of ElemenTARY SCHOOL.

RESUMEN Este trabajo tuvo por objetivo analizar aspectos de la docencia de 11 profesoras que son reconocidas por sus pares como referencia de práctica docente porque enseñan en la perspectiva de "hacer aprender algo a alguien" en contraposición a la idea de enseñanza como acto de "profesar un saber" como distingue Roldão (2007). Teóricamente se apoyó en Roldán, para abordar la doble transitividad y la mediación en el proceso de enseñanza aprendizaje, y en Shulman, en lo que se refiere a la base de conocimiento profesional docente. Metodológicamente consideró la técnica de la bola de nieve, que utiliza cadenas de referencias y entrevistas semiestructuradas. Las once profesoras de escuela pública ubicadas en el estado de Río de Janeiro / BR participaron en la investigación. El análisis de los datos se construyó en tres ejes: concepciones de enseñanza; los saberes movilizados por las profesoras para enseñar en la perspectiva de "hacer aprender algo a alguien"; estrategias de enseñanza elaboradas por las profesoras. Los resultados indican que las profesoras conciben la enseñanza como acto investigativo, el profesor se presenta como un investigador y creador de nuevas y variadas estrategias para enseñar, el proceso pedagógico de mediación del profesor entre el conocimiento y el alumno involucra múltiples saberes para suplir la necesidad de la clase y de los alumnos individualmente.

Palabras Clave: Didáctica y Docencia; La enseñanZa y el aprendizaje; EnseñanZa FUNDAMENTAL I. 


\section{INTRODUÇão}

Este artigo se propõe a relatar um estudo sobre a docência de 11 professoras que são reconhecidas pelos seus pares como referência de prática docente porque ensinam na perspectiva de "fazer aprender alguma coisa a alguém" em contraposição à ideia de ensino como ato de "professar um saber", conforme distingue Roldão (2007). Trata do professor no contexto da escola básica, em uma perspectiva direcionada para a base de conhecimento profissional docente, mais especificamente no que tange às práticas didáticas diferenciadas e significativas segundo o crivo de seus próprios colegas, seus pares.

Ao voltarmo-nos para práticas que resultam em um aprendizado significativo a partir de um ensino que se diferencia dos demais, porque mobiliza distintos saberes e fazeres, almejamos dar relevo ao trabalho bem-sucedido de professores para ensinar e aprender em situações concretas de sala de aula da educação básica.

Nesse sentido, investigamos a docência de um grupo de professoras dos anos iniciais do ensino fundamental de escolas públicas sediadas no Estado do Rio de Janeiro/BR, buscando compreender como elas conseguem desenvolver seus saberes e fazeres para ensinar diferenciadamente da lógica vigente, centrada na transmissão, repetição e assimilação, e serem reconhecidas pelos seus pares por conta de sua prática.

Um conceito-chave para o nosso estudo reside na perspectiva de ensinar defendida por Roldão (2007), que discute dois modos prevalecentes de ensino: "professar um saber" e "fazer aprender alguma coisa a alguém". O primeiro envolve predominantemente a ação do professor, enquanto o segundo abarca a ação de ambos os sujeitos envolvidos na relação - professor e aluno. O segundo modo de ensinar se assenta em uma perspectiva de prática docente que exige, de acordo com a autora, a dupla transitividade e a mediação. A primeira transitividade estaria em ensinar algo (o conteúdo, aquilo que precisa ser aprendido) e a segunda transitividade se completaria na afirmação de que se ensina algo a alguém. É justamente a segunda transitividade que dá sentido ao processo, visto que quando o aluno aprende o ensino se realiza, a partir de uma relação de mediação feita pelo professor.

Desse modo, este relato se ocupa em apresentar as concepções de ensino e os saberes mobilizados pelas professoras para ensinar, bem como, as estratégias didáticas predominantes no processo de mediação do ensino.

\section{Perspectiva metodológica}

Para atender ao objetivo de investigar a docência de professores dos anos iniciais do Ensino Fundamental, que ensinam na perspectiva de "fazer aprender alguma coisa a alguém", segundo atestam os seus próprios pares, desenvolvemos uma pesquisa teórico-empírica. As percepções dos próprios pares sobre práticas diferenciadas de professores da educação básica nos pareceram um indicativo mais coerente, pois todos fazem parte de um mesmo contexto, conhecendo os seus prós e contras. A indicação feita pelo colega representou, portanto, a estratégia definidora dos sujeitos da pesquisa. Participaram do estudo 11 professoras dos anos iniciais do Ensino Fundamental com atuação em escolas públicas municipais, estaduais ou federais localizadas no Estado do Rio de Janeiro. 
Trabalhamos com a técnica da bola de neve (BIERNACKI \& WALDORF, 1981). A amostragem, nesse caso, não é probabilística, prevalecendo a utilização de cadeias de referências. Por conta disso, não pode ser possível determinar a probabilidade de seleção de cada participante na pesquisa, mas justamente por essa especificidade torna-se útil para estudar determinados grupos difíceis de serem acessados. Essa técnica pode ser utilizada em pesquisas sociais em que os participantes iniciais de um estudo indicam novos participantes, que por sua vez apontam outros participantes e, assim sucessivamente, até que seja alcançado o objetivo proposto (o "ponto de saturação").

O desenvolvimento da pesquisa com base nessa estratégia deu-se do seguinte modo: o "pontapé" inicial foi dado quando buscamos documentos e/ou informantes-chave, nomeados como sementes, para localizar pessoas com o perfil necessário para a pesquisa, dentro de determinada população. Com a ajuda da semente, os primeiros contatos foram realizados e, na medida em que as entrevistas foram sendo feitas, solicitamos que os entrevistados apontassem novos contatos a partir de sua própria rede pessoal. De posse do material pesquisado, interpretamos os dados utilizando a análise de conteúdo na perspectiva de Bardin (2011).

Do conjunto de trinta indicações, conseguimos fazer 12 entrevistas, sendo que uma foi descartada devido ao fato de que o professor entrevistado exerce a sua docência na segunda etapa do Ensino Fundamental. Assim, nosso estudo foi desenvolvido com uma rede de 12 professores, dos quais 11 se tornaram sujeitos da pesquisa. A realização das entrevistas obedeceu ao movimento da rede social dos entrevistados, em que a maior parte trabalha no município de Duque de Caxias/RJ. Dessa forma, oito entrevistas foram efetuadas no município de Duque de Caxias/RJ, duas no Rio de Janeiro/RJ, uma em Magé/RJ e uma em Nilópolis/RJ.

No que tange à escolarização básica, a maioria estudou em escola pública, com exceção de apenas uma professora, que estudou em escolas da rede privada. Seis professoras, além de estudarem no âmbito de escola pública, também estudaram em escolas privadas. Do grupo, sete professoras fizeram o curso Normal anterior ao curso de Licenciatura, e apenas uma não fez o curso de Licenciatura, habilitando-se como professora exclusivamente por meio do curso Normal. O curso de Pedagogia, feito por sete das onze entrevistadas, foi cursado predominantemente no contexto universitário. Três professoras se graduaram em Letras e uma, anterior ao curso de Letras, fez o de Matemática. Quanto ao curso de especialização, oito professoras deram continuidade à formação por meio da Pós-Graduação Lato Senso, tendo feito curso nas áreas de Psicopedagogia, Educação Infantil, Educação Especial e Linguística. Cinco fizeram Mestrado e uma fazia o Doutorado na época da entrevista.

No que diz respeito à atuação profissional, a média de tempo de magistério é de 18 anos. As professoras entrevistadas trabalham em sala de aula do Ensino Fundamental I, do $1^{\circ}$. ao $5^{\circ}$. Ano de escolaridade, há muito tempo, reunindo bastante experiência na docência. Dália, ${ }^{1}$ a que tem menos tempo de docência trabalha como professora há nove anos; e Gardênia, a que tem mais tempo, trabalha há 32 anos. Duas - Açucena e Íris - trabalham na rede federal, no Colégio Pedro II. As demais trabalham em rede municipal de ensino, sendo a maioria de Duque de Caxias e apenas uma - Petúnia - de Magé e de Itaboraí.

Para nomear os sujeitos usaremos codinomes, buscando resguardar eticamente os participantes do estudo. 
Como se pode notar, trata-se de um grupo de professoras do Ensino Fundamental I devidamente qualificadas, com inserção na escola pública e com tempo expressivo de trabalho em sala de aula. Esse grupo se revela, segundo os próprios colegas de trabalho, como professoras que ensinam de modo significativo, favorecendo que seus alunos aprendam o conhecimento de forma investigativa, crítica e problematizadora, como defende Roldão (2007), na perspectiva de ensinar que se contrapõe à de professar um saber.

Um aspecto importante da pesquisa pautou-se justamente pela investigação dessas professoras, que já estão inseridas e fixadas nos seus contextos de atuação e, portanto, não são iniciantes na carreira, ultrapassando os cinco primeiros anos de exercício profissional, além disso, alcançando resultados satisfatórios, a ponto de seus pares as reconhecerem por ensinarem de forma diferenciada da transmissão. Nosso interesse em relação a esse grupo tão especial foi o de, por meio de suas concepções e práticas de ensino, discutir teorizações e fundamentações conceituais e procedimentais sobre a relação que envolve os professores e alunos em torno do conhecimento, em uma tentativa de contribuir para uma Didática do Ensino Fundamental I.

Nas suas narrativas, encontramos traços de uma identidade docente marcada pelo desejo pela profissão, pela afinidade com o trabalho e pela realização que o ofício proporciona, como se pode depreender da fala da professora Íris:

Queria ter feito o Curso Normal, mas como eu estudava no Pedro II, minha fa-
mília meio que "ah, tem certeza, vai sair do Pedro II”? Era uma escola federal,
conceituada... pra fazer Normal e depois se arrepender... eu falei: então, vou
terminar meu ensino médio. Mas, quando eu terminei o ensino médio, eu já fui
estudar Educação. Procurei uma Faculdade de Educação, me formei na UFF,
fiz Pedagogia na UFF. Eu queria ser professora. E assim, não me vejo fazendo
outra coisa.

Como já sinalizado, a maior parte do grupo é oriunda de escola pública, possuindo, em comum, um comprometimento com esse espaço de formação humana para a vida social e para a preparação para o trabalho cultural e político das novas gerações. Ainda na voz de Íris: "A minha vida inteira, meu mestrado na UERJ também. As especializações todas em universidades públicas, sempre em escola pública".

Outro traço notado na caracterização das professoras é o apreço pela leitura e pelas diferentes práticas culturais na vida e no trabalho, favorecendo que, no exercício da docência, o ensino da leitura transcenda ao domínio técnico e alcance os alunos e sua visão de mundo. No dizer de Dália: "O meu irmão escrevia textos, lia muito. E a minha mãe ensaiava os teatros, os versos nordestinos. Então eu cresci assim. E assim eu faço com meus alunos". Essa relação especial com a leitura é por nós compreendida e defendida como uma condição imprescindível para o exercício de uma docência crítica, criativa, investigativa e emancipadora.

Um aspecto que consideramos de muita relevância é o investimento na formação docente como condição para o desenvolvimento profissional. As professoras investem em formação continuada para melhorar o modo de ensinar, demostrando com isso que possuem um compromisso com a escola pública, compreendendo-a como espaço de educação democrático, crítico, plural e inclusivo. 


\section{A didática NAS CONFIGURAÇões do TRABalHo dOCENTE dE PROFESSO- RAS DOS ANOS INICIAIS DO ENSINO FUNDAMENTAL}

\subsection{Sobre a docência}

Segundo Gatti (2010), a função social da escola é a de ensinar às novas gerações o conhecimento acumulado e consolidar valores e práticas coerentes com nossa vida civil. Nesse sentido, a responsabilidade do professor está atrelada a grandes desafios para fazer que os seus alunos adquiram habilidades necessárias para compreenderem as relações que existem entre os problemas atuais e os conteúdos abordados em sala de aula. Essa consciência do professor como formador e a sua responsabilidade social aparece com muita evidência na fala das professoras, como se pode depreender do depoimento de Magnólia:

Eu sou professor e ele é aluno, mas a relação é dual. Eu preciso aprender para ensinar para ele, ele aprende e ele me ensina, então é o tempo todo nessa relação. E não é uma relação finita, não é uma relação pronta. Eu sou professor, eu já sei tudo? Eu sou docente e estou me tornando docente a cada minuto da minha vida! Porque as transformações vão agregando conhecimentos pra gente, a maturidade vai agregando experiência pra gente, e as relações humanas também vão transformando esse conhecimento, reforçando nossa responsabilidade.

Acreditamos que esse compromisso de responsabilidade social faz parte do universo docente por conta da natureza da própria função, mas muitas das vezes a concepção de ensino de cada docente tem papel crucial no desenvolvimento do seu ofício. As professoras participantes se situam na concepção de ensino que se contrapõe à de professar um saber, afirmando-se por fazer aprender alguma coisa a alguém e, portanto, situando-se na perspectiva de um ensino investigativo, problematizador e dialógico. A fala de Amarílis é pontual nesse sentido:

Eu acho que ensinar, assim, não está mais no transmitir conhecimento, eu acho que ensinar pra mim é despertar a curiosidade sabe? O negócio não me deixa tão feliz quando a criança repete tudo o que eu falo. Ela me deixa muito feliz quando ela fica curiosa com aquilo que eu falo, que eu provoco, que eu proponho, sabe? Eu acho que aí eu fiz o mais importante que é despertar a busca do conhecimento. Eu não quero transmitir só conhecimento, eu quero transmitir pra ela a busca e a vontade de querer conhecer. Isso pra mim que faz sentido assim, de querer ensinar.

Para Roldão (2007), a dicotomia entre ensino transmissivo versus ensino mais ativo deve ser superada, pois a função de ensinar precisa ser compreendida como um plano integrador caracterizado pela dupla transitividade e pelo ligar da mediação entre quem promove intencionalmente a aprendizagem de alguma coisa a alguém que se considera necessário em determinado contexto. Dessa forma, a ação de ensinar dos professores assume sua função social ancorada em um saber próprio que outros atores sociais não dominam. Os professores são então especialistas no que fazem, pois mobilizam saberes para despertar nos alunos a curiosidade para aprender de forma significativa. 
Sendo assim, percebemos que as professoras investigadas concebem o ensino como ato investigativo, despertador, que exige do professor um domínio de conhecimento para ensinar. Elas despertam a curiosidade, buscando e oferecendo caminhos metodológicos para que o aluno aprenda, como reforça a fala da professora Íris:

\begin{abstract}
Não é transmitir conhecimento apenas, não é chegar com a informação pronta porque muitos já têm muitas informações. Algumas informações equivocadas e a gente tem que ... é lógico, dar nossa contribuição pra isso. Então eu acho que a função docente hoje, a docência é nada mais que você provocar, instigar e organizar também, mas sistematizado.
\end{abstract}

Roldão (2005) considera a mediação do professor como um ato representativo socialmente de sua profissão, respeitado na sua essência e exercido por quem de direito. Dessa forma, fazer aprender alguma coisa a alguém se torna diferente de "quem sabe ensina", pois o profissional de ensino saberá mobilizar seus saberes, dentro do seu estatuto de profissionalidade, porque é um especialista na ação de ensinar, que é a sua especificidade. E outros atores sociais, mesmo que saibam muito saberes conteudinais, poderão não saber fazer.

A mediação do professor dentro dessa perspectiva também pode ser compreendida como ação de equilíbrio para perceber as necessidades entre dois polos, intercedendo para uma aprendizagem que seja satisfatória e completa, respeitando as especificidades das situações e dos indivíduos envolvidos nesse processo.

Nessa perspectiva, o professor é um profissional de ensino que constrói a passagem de um saber ao aluno, conforme defende Açucena:

Sempre achei que a função do professor é que o aluno aprenda. Se eu ensino,
e o aluno não aprende, eu na verdade não ensinei (...) [é o professor] que tem
que oferecer formas diferenciadas pra que qualquer aluno consiga aprender,
qualquer coisa! Claro que tem possibilidade de acordo com faixa etária, com
interesses... mas eu acredito que com o tempo a gente consiga fazer os alunos
aprenderem tudo aquilo que eles se propõem a aprender e o que a gente profes-
sora considera também que é essencial que eles possam aprender.

Assim sendo, somente o professor, com seus conhecimentos e orientação intencional nas ações de ensino, conduz à possibilidade efetiva do esforço do aluno se traduzir na apreensão do saber que se pretende adquirido.

Nesse sentido, a docência para nossas investigadas envolve responsabilidade social, e mais que responsabilidade, envolve um comprometimento com a aprendizagem do aluno. Por conta disso, a concepção de ensino demonstra um investimento consciente que não se apresenta como processo estático, mas em constante movimento. Dessa forma, a função de ensinar não é compreendida como apenas passar um saber, mas antes, torna-se uma função definidora do profissional professor.

Para Roldão (2007), os professores tornam-se profissionais indispensáveis quando fazem aprender alguma coisa a alguém, e, esse processo envolve a organização e estruturação de um conjunto de ações que mobilizam diversos saberes. Quando o professor planeja suas aulas tendo como centralidade o seu aluno e o grupo em sala de aula, seu trabalho é alar- 
gado, assumindo uma dimensão plural, pois envolve o contexto do aluno e da comunidade, amparado por muito estudo e investigação.

Roldão (2007) propôs um conjunto de características que distinguem o conhecimento profissional docente a partir do que chama de "saber ideal", compreendido como saber eficaz da função de ensinar dentro de uma lógica normativa, e da interpretação da prática real apoiada em investigação sobre experiências e práticas docentes de formação. A autora enumera cinco características que são: natureza compósita; capacidade analítica; natureza mobilizadora e interrogativa; meta-análise e comunicabilidade e circulação. Uma das características do conhecimento profissional docente que o distingue é sua natureza compósita, diferente de composta, pois se trata de saberes que vão se constituindo de tal forma que não é possível, ao longo do tempo, identificá-los isoladamente, pois se transformam e passam a fazer parte uns dos outros. Desse modo, o conteúdo científico será transformado em conhecimento didático do conteúdo por meio de ação transformativa perante uma situação de ensino.

As falas das professoras Íris e Magnólia sobre como fazem para ensinar, confirmando uma concepção de ensino centrada na problematização, nos ajudam a entender esse processo:

Eu gosto sempre de fazer assim, orientar assim: eu tenho que trabalhar com a questão do conceito com o menino então eu faço como se fosse uma tempestade de ideias com eles. E eu vou fazendo as minhas mediações a partir daquilo ali e eu gosto, eu tenho por costume ao final das aulas sempre pedir pra que eles me registrem algo daquilo que a gente trabalhou.

Eu tento incentivar muito. Eu não gosto de livro parado! Eu acho que livro tem que circular, ele tem que andar! Então ... tem gente que tem maior cuidado com aquele livro e tal ... livro novo melhor ainda! E ao longo dos anos eu tenho visto que isso tem me dado retorno. Eu tenho um espaço na sala de aula que eu vou renovando, trocando com livros meus, livros que eu ganho, com livros que eu pego na biblioteca, onde tiver. E eu vou estimulando, eles levam os livros pra casa, um indica pro outro e assim vai!

A respeito da comunicabilidade e circulação, Roldão (2007) afirma ser uma característica importante na construção do conhecimento profissional docente, porque é uma dimensão que afasta muito os docentes da posse de um conhecimento profissional pleno por conta da dificuldade de explicitar o conhecimento tácito sobre suas práticas de ensino. A autora propõe que os professores invistam nesse conhecimento tácito, sistematizando-o e articulando-o para que possa ser divulgado entre seus pares e se torne, então, conhecimento passível para comunicação, reconhecido como produção dos docentes em ação, fortalecendo a representação social dos professores. Dentro dessa lógica de relação comunicacional entre pares, encontramos aproximações na proposta da autora e na prática das professoras participantes, que seguem representadas pelas falas de Amarílis e Hortência:

[...] fui dar aula numa escola e nessa escola fui alfabetizar. Na verdade, numa turma de alfabetizar de 5 anos e, assim, a pessoa que estava coordenando, ela me ensinou muito essa questão do letramento e tudo mais, foi uma experiência muito legal... 
Porque quando você está em formação, você está em contato com pessoas que passam por diferentes situações, você compartilha materiais ... que é aquela história: ah, o que serve pra um não serve pro outro! Mas te dá ideia de como fazer melhor. Acho que ser professor é compartilhar de uma profissão que está sempre em estudo mesmo, em pesquisa. Talvez ser professor seja ser um pesquisador em potencial, pode ser esse tipo de relação com o conhecimento.

Dessa forma, percebemos que o conhecimento profissional docente precisa ser construído tendo como base uma teorização prévia, tutoreada e discutida da ação docente individual e observada nos outros. Roldão (2007) afirma que, nesse sentido, a função de ensinar é socioprática, com saber teorizador, compósito e interpretativo, que emerge de vários saberes formais e do saber experiencial que são investigados e questionados.

\subsection{Sobre os saberes mobilizados para ensinar}

Shulman (1987), com base em pesquisa com profissionais do ensino considerados peritos, propõe maior atenção ao pensamento do professor para perceber como este mobiliza seus conhecimentos em prol da aprendizagem de seus alunos por meio de um processo de pensamento, raciocínio e ação. Para Shulman (1987), os conhecimentos para ensinar são acionados por intermédio de seis passos do raciocínio pedagógico: compreensão, transformação, instrução, avaliação, reflexão e nova compreensão. Esse movimento permite ao professor compreender como os seus alunos aprendem e, assim, planejar suas intervenções continuamente.

No que tange ao planejamento, é necessário considerar, segundo Shulman (1987), o conhecimento da matéria a ser ensinada. De acordo com o autor, é importante que o professor compreenda as estruturas da matéria, os seus princípios da organização conceitual, bem como, os de investigação.

\footnotetext{
"E quando você vê que isso não é uma coisa específica de uma criança, e você vê que isso é coisa que acontece com grande maioria das crianças, nós começamos a nos questionar como ensinar melhor, como fazer com que essa criança compreenda as coisas que já foram estabelecidas pela sociedade. Porque os conhecimentos são todos estabelecidos... o alfabeto não é o que é porque é assim que tem que ser, é porque foi uma decisão de uma comunidade, de um grupo, de uma sociedade". Professora Hortência.
}

Esses são saberes que, segundo Shulman, decorrem das teorias de ensino, domínio do conteúdo, que são necessários para o início do processo de raciocínio pedagógico. O outro conhecimento é o conhecimento do currículo, ou a necessidade que envolve compreender os programas de currículo como política em relação ao conhecimento oficial. Nesse sentido, as professoras Açucena e Camélia se mostram atentas:

"E aí eu tenho que encaixar não só os conteúdos que a gente diria, conteúdos conceituais, conteúdos factuais, os descritores de Língua Portuguesa, Estudos Sociais ... mas também os descritores que são comuns a todas as áreas que são os de formação de cidadania, os de formação de atitudes necessárias ao traba- 
lho, a criança aprender a manusear uma régua, a recortar enfim... tudo isso tem que ser pensado... eu tenho uma lista assim de coisas que eu não posso esquecer de fazer, pra me lembrar disso sempre".

“[...] numa mesma semana fazer três jogos ... é demais entendeu? ou quando você vai trabalhar um conteúdo mais pesado, e você tá com os alunos de Matemática e diz: poxa, eu vou trabalhar com quarto, quinto ano com conteúdo pesado de história, eu vou trabalhar com uma coisa mais lúdica na área de linguagem, faz um jogo na Matemática ... equilibrar um pouco essas atividades ... [...]"

Outra categoria de conhecimento é o conhecimento pedagógico do conteúdo, que envolve a relação que o professor estabelece entre o conhecimento da matéria a ser ensinada e o conteúdo pedagógico. A professora Violeta demonstra como recorre a esse conhecimento:

\begin{abstract}
"Então, assim, a minha aula é muito baseada em perguntas, e é o que eu falo pra eles, é "pergunte". Mais importante do que a gente ter respostas é a gente saber perguntar. Então assim, todas as aulas são baseadas nisso, é o planejamento sempre do movimentar. Eles têm algumas atividades próprias e que esse ano eu não consegui fazer, mas eu sempre faço nas turmas, que é uma leitura diária, o aluno que vai, ele escolhe uma leitura para compartilhar com os colegas, o jornal falado, que é uma notícia que sirva pra gente discutir alguma coisa, então eles levam".
\end{abstract}

Sobre o conhecimento pedagógico do conteúdo, vale a pena dar relevo à afirmação de Shulman (1987), que o considera como um tipo de conhecimento em que o professor é protagonista, pois emerge de sua construção pessoal, que envolve suas concepções de ensino.

Outra categoria de conhecimento é o conhecimento dos alunos e de suas características, ficando evidente nas práticas das professoras, como é possível notar nas falas de Magnólia e Petúnia, a seguir:

"[...] mostrar algo diferenciado daquilo que ele tem, a gente trabalha com escolas públicas, com comunidades com várias dificuldades com vários problemas, com alunos com várias situações familiares graves em sua grande maioria ... e eu tento com a minha docência mostrar pra ele que tem um mundo, tem um mundo lá fora e ele precisa conhecer esse mundo, precisa entender esse mundo ... [...]"

"Eu procuro saber primeiro o que ele sabe, eu vou lá no que a criança já sabe, que nível essa criança está, o quanto essa criança sabe e onde ele parou. Aí sim, eu parto de onde ele parou. ...o que eu menos me importo é se essa criança ... por exemplo, se ela está no segundo ano e não está alfabetizada... por quê? Em algum nível ela está! Eu vou lá no nível em que ela está".

Para nossas depoentes, investigar a origem de seus alunos, o contexto onde vivem, situa-se como condição necessária para o desenvolvimento de estratégias com finalidades pedagógicas para o processo de ensino-aprendizagem.

A última categoria são os conhecimentos dos fins educacionais, que envolvem metas, propósitos e os fundamentos filosóficos e históricos da Educação. Esse conhecimento pa- 
rece muito presente também no dia a dia das professoras, principalmente porque sentem o impacto das avaliações externas e suas implicações:

\footnotetext{
"E você refaz essa avaliação no segundo semestre, e você pega ele no outro ano e torna fazer... mas a prefeitura recomenda que os trabalhos em si sejam para observações diárias. É claro que você não dá ...eu separo a turma em cinco blocos porque são vinte e cinco, e ficam cinco pra cada um. Então a gente vai ler hoje segunda, os cinco primeiros vão ler, amanhã são os outros cinco. Então eu sigo a recomendação da prefeitura, eu até ponho aqui segundo a observação diária... eu começo o relatório... foi possível verificar que o aluno apresentou avanço ou não apresentou avanços". Professora Verônica.
}

Para Roldão (2007), assim como para Tardif (2002; 2000), os saberes que os professores mobilizam para ensinar são amalgamados, compósitos e decorrem, em geral, de uma postura investigativa do conhecimento tácito que deve ser sistematizado para circular entre pares, tornando o trabalho do professor, no que toca ao ofício de ensinar, bastante complexo.

Nesse sentido, Roldão e Shulman nos ajudam a confirmar em nossa pesquisa que as professoras que foram indicadas pelos seus pares, por terem uma prática pedagógica que se diferencia das demais, mobilizam diversos saberes para ensinar da forma que ensinam. Ao inventariar a que concepções de ensino estão atrelados os saberes, os conhecimentos de base dessas professoras, percebe-se que levam em conta o contexto político-social dos alunos para planejar suas aulas, o conhecimento prévio dos alunos como diagnóstico inicial para tomada de decisões, buscam investigar mais conhecimentos pedagógicos além dos abordados na formação inicial para dinamizar sua prática, compartilham com seus pares e buscam soluções em grupo neutralizando a sensação de solidão, assim como, procuram estar atentas às políticas públicas que interferem diretamente em suas salas de aulas.

Podemos então afirmar que as professoras investigadas possuem uma base de conhecimento robusta e variada, construída ao longo de suas trajetórias de formação e de atuação. Assim como Roldão (2007) nos auxilia ao lembrar que esses saberes são compósitos e integrados uns aos outros, Shulman (1987) também elucida que eles aparecem quando o professor elabora seu pensamento para ensinar por meio do processo de raciocínio pedagógico. Mas como fazem isso? Quais estratégias de ensino utilizam para atingir suas intenções pedagógicas?

\subsection{Sobre as estratégias de ensino}

O conceito de estratégia é difuso e sofre influência de processos educacionais e sociais. Segundo Roldão (2009), podemos encontrar o conceito de estratégia atrelado às técnicas de ensino em determinada época. Dessa forma, a autora deixa claro que a estratégia que o professor usará estará vinculada com sua própria concepção de ensino, ou seja, se o professor deposita atenção maior na organização dos conteúdos, separando a aprendizagem do aluno como ato independente, torna-se estratégia voltada para a organização lógica dos conteúdos.

A ideia de estratégia que a autora defende, e que se contrapõe à exposta, toma o ato de ensinar centrado nas duas dimensões a que sua ação se dirige: o conhecimento/conteúdo curricular e o aluno. 
Nessa perspectiva, para compreender como se desenvolve o processo de ensinar pelas professoras participantes, indagamos sobre o que levam em conta quando planejam suas aulas.

\begin{abstract}
"Eu utilizo esses diagnósticos, eu faço esses diagnósticos tanto de linguagem quanto de matemática. Das outras áreas e que isso não está muito bem resolvido assim, a gente pensa em coisas importantes e a gente vai tentando trabalhar aquilo e vamos fazendo as negociações com os outros conteúdos né. Usando técnicas didáticas, usando outras técnicas também para inserir alguns assuntos, mas a linguagem e a matemática são muito mais fáceis de planejar pra a turma por conta desse trabalho que eu falei individualmente que eu faço de chamar na mesa para fazer os meus diagnósticos". Professora Hortência.
\end{abstract}

Pela fala dessa professora, é possível perceber que no ato de planejar levam-se em conta as especificidades coletivas e individuais, propondo trabalhos que se dirijam à necessidade do aluno individual e em grupo também. É uma ação que envolve estudo e pesquisa, onde o planejamento ocorre individualmente, no coletivo e com respeito à organização institucional, mas, acima de tudo, com atenção para o que aluno precisa saber, desenvolver e atender enquanto objetivos educacionais.

Segundo declaram nossas depoentes, as estratégias para ensinar na perspectiva crítica são diversas, envolvendo trabalho do aluno, do professor, do aluno com aluno e do aluno com professor. Trata-se de um ensino participativo, com mobilização de diferentes linguagens, como explicam Amarílis e Açucena:

"Ah, o que eu faço muito é meio debate assim, discutir mesmo! E uma coisa que eu faço muito assim é teatro. Não teatro mesmo, mas assim, encenação. Coisas históricas, até em Matemática dá pra eles entenderem as coisas. Interpretarem, aí vai agora fulano, fala isso... agora faz isso, é aquela questão mesmo de ilustrar e uma das coisas mais fortes é desenhar. Eu desenho muito no quadro".

"É.... eu uso muito o corpo da criança pra ela aprender. Eu uso muito as suas próprias sensações e experiência, uso muito seus prazeres e gostos como recursos básicos e fundamentais pra eu primeiro motivar as crianças para aprender e seguindo a linha delas, a própria oralidade da criança é um recurso fundamental pra mim. Trabalho com o que tiver. Recurso é tudo que você tiver a mão, na mente, no corpo para usar com a criança... depende só da nossa vontade de usar."

As professoras parecem construir e reconstruir estratégias para ensinar. Roldão (2007) afirma que todos os saberes que os professores utilizam são incorporados aos já existentes, formando um conhecimento novo, compósito na sua essência e com intenção para ensinar. Como afirmado pela autora, as estratégias que os professores recorrem acompanham sua concepção de ensino, e nesse sentido é possível afirmar que as professoras se aproximam do conceito de fazer aprender alguma coisa a alguém, com uma ação inteligente e fundada em domínio seguro de saber, que emerge de vários saberes formais e do saber experiencial. Dentro dessa lógica, do saber que emerge da experiência, a organização do tempo e a gestão da sala de aula são aperfeiçoadas, para beneficiar o ensino e o trabalho do professor, como fica claro na fala de Açucena, a seguir: 
"Eu deixo eles escolherem o lugar, eu faço algumas trocas, eu arrumo de outro jeito, mas assim... eu estou sempre mais perto dos alunos que precisam mais, eu vou trocando eles de lugar, mas eles não saem muito longe de mim então isso é uma organização física básica na sala. Eu chego meia hora antes todo dia, eu arrumo a sala, quando os alunos entram a sala já está arrumada, os materiais que eu vou usar já estão dispostos. A rotina do dia já está feita no quadro pra eu ler e discutir com eles, ver o que a gente vai conseguir dar conta de fazer, o que não vai... negociar algumas coisas que são possíveis. Enfim, isso aí já é básico".

Para que essa organização funcione de forma favorecedora ao ensino em sala de aula, as relações exigem autoridade, respeito e, muitas das vezes, precisam ter muita firmeza por parte das professoras. Mas, elas afirmam que também primam por uma relação em que o afeto tem papel central nessa interação. Existe a construção diária de respeito mútuo do professor com o aluno e do aluno com aluno, onde a honestidade, a empatia e o carinho são construções diárias. A fala a seguir reforça essa afirmação:

"Olha, eu permito que os meus alunos falem tudo. Com respeito é claro, mas
eles me contam coisa da vida deles, até coisas que eu não quero saber. Porque
eu acho que a gente precisa estabelecer uma relação de verdade. Então assim, se
eu prometo alguma coisa, eu faço questão de cumprir. Quando a gente combina
alguma coisa, tanto da minha parte quanto da parte deles, eles sabem que foi um
tratado que nós fizemos". Professora Dália.

A respeito da avaliação do processo ensino-aprendizagem, partimos da afirmação que Diaz Barriga (1999) faz em que o exame (avaliação) é um efeito das concepções sobre aprendizagem, não o motor que transforma o ensino. Entendemos que o que transforma o ensino são ações eficazes para ensinar daqueles que constroem possibilidades para as construções do novo, do ser humano. Nesse sentido, as professoras indicadas parecem corroborar com nosso ponto de vista, quando declaram que:

"Como eu avalio o ensino e a aprendizagem? Eu avalio o ensino pela voz dos meus alunos, pela voz dos pais, pela minha própria autoavaliação, pela avaliação das minhas chefias imediatas”. Professora Açucena.

"Sim, é sempre! O tempo todo. Cada um tem uma especificidade, mas eu valorizo muito a oralidade também, mesmo que ele não consiga registrar, eu avalio muito a oralidade ... porque tem muitos alunos que falam, mas não conseguem ainda botar no papel dele. Eu faço registro do que ele compreendeu e que eu consigo verificar[...]”. Professora Petúnia.

A avaliação do ensino e da aprendizagem para nossas depoentes envolve diferentes sujeitos, saberes e fazeres. A necessidade de classificar o aluno no que tange à sua aprendizagem está presente no processo, por força institucional, mas não o domina. Dessa forma, a avaliação é um movimento que tem recursos diversos, atrativos e intencionais para a efetivação do aprendizado.

A avaliação, assim como o planejamento, são componentes importantes do trabalho docente, subsidiando as escolhas, as propostas e as intervenções feitas para que os alunos 
aprendam aquilo que se almeja. Nossas depoentes deixam ver que o planejamento e a avaliação consideram as diretrizes institucionais, as propostas construídas coletivamente e as necessidades específicas da classe como um todo e de cada aluno na sua particularidade.

Por essa razão, as estratégias de ensino mobilizadas na docência coadunam com a perspectiva da mediação e da dupla transitividade, constituintes de uma concepção de ensino voltada para fazer aprender alguma coisa a alguém. A aula não é um espaço de exposição pelas professoras, ainda que elas aconteçam. A aula é um espaço/tempo de trabalho dos alunos e das professoras, em que cada um e todos dialogam, problematizam, comparam, levantam hipóteses, experimentam, redigem, refazem até que a aprendizagem se consolide.

\section{CONSIDERAÇões FINAIS}

Quando nos propusemos a analisar aspectos da docência de 11 professoras que são reconhecidas pelos seus pares como referência de prática docente porque ensinam na perspectiva de "fazer aprender alguma coisa a alguém" em contraposição à ideia de ensino como ato de "professar um saber", conforme distingue Roldão (2007), tínhamos como diretriz o desejo de desenvolver um percurso investigativo que nos permitisse conhecer, analisar, discutir, refletir sobre a prática docente na primeira etapa do Ensino Fundamental, experimentada por professores com atuação na escola pública e com ela comprometidos, que se destacam porque ensinam de forma diferente da transmissão.

Com os olhos fitos no trajeto percorrido, percebemos que o grupo investigado, formado por 11 professoras escolhidas segundo indicação de seus pares, foi estratégico para que chegássemos onde chegamos, conforme metodologicamente planejamos. Por meio dos depoimentos colhidos, das falas analisadas, das memórias narradas, pudemos discutir aspectos da docência, próprios de uma Didática do Ensino Fundamental I, visto que eles nos dão importantes pistas sobre o processo ensino e aprendizagem, no que toca ao tratamento dos conteúdos, à definição das estratégias de ensino, à relação entre professores e alunos, ao planejamento do trabalho pedagógico, à avaliação do processo ensino-aprendizagem, sempre em consonância com determinada concepção de ensino, aquela que motivou a realização deste trabalho: "fazer aprender alguma coisa a alguém” (ROLDÃO, 2007).

Verificamos que a docência de nossas investigadas se sustenta por meio de uma prática de ensino investigativa, problematizadora e dialógica. Elas concebem o ensino como ato investigativo, despertador, que exige do professor um domínio de conhecimentos plurais para ensinar. Conseguem despertar a curiosidade e oferecem caminhos metodológicos para que o aluno aprenda. Buscam várias formas de mediação para chegar ao aluno. Essa forma de ensinar envolve responsabilidade social, mais que isso, envolve um comprometimento com a aprendizagem do aluno. Por conta disso, essa concepção de ensino exige um investimento consciente que não se apresenta como processo estático, está em constante movimento.

Existe uma comunicação entre os professores que auxilia nas reflexões sobre as formas de ensinar, condição importante no nosso entender para que a ação de ensinar permita que o professor possa agir gerando conhecimento sistematizado, refletido na ação encadeada, auxiliando na construção de novas práticas. Concomitante a isso, as professoras primam por investigar a origem dos alunos, o contexto em que vivem, demostrando ser 
esta uma estratégia necessária com finalidades pedagógicas coerentes para o processo de ensino aprendizagem.

No tocante às estratégias elaboradas pelas professoras para desenvolverem sua docência, constatamos que, por meio do ato de planejar, as especificidades coletivas e individuais da classe de alunos se firmam como condição primordial para a condução do processo. A busca por trabalhos que se dirijam para a necessidade do aluno individualmente e em grupo é uma ação que envolve estudo e pesquisa, onde o planejamento ocorre individualmente e no coletivo, com respeito à organização institucional, mas acima de tudo, com atenção para o que o aluno precisa saber. Esse planejamento espera alcançar também os objetivos educacionais, por intermédio de propostas de ensino que envolvam o trabalho do aluno, do professor, do aluno com aluno e do professor com o aluno. Assim, a aula não é um espaço de exposição pelas professoras, ainda que isso aconteça, mas antes é espaço/tempo de trabalho dos alunos e das professoras, em que cada um e todos dialogam, problematizam, comparam, levantam hipótese, experimentam e refazem, até que a aprendizagem se consolide.

As professoras constroem e reconstroem recursos para ensinar, utilizando tudo ao seu alcance. Esse investimento, segundo elas, precisa de uma organização funcional de forma que favoreça o ensino em sala de aula, onde as relações exigem uma autoridade, respeito e, muitas das vezes, firmeza por parte das professoras. O respeito mútuo é uma construção diária entre o professor e o aluno, entre o aluno e o aluno, onde a honestidade e a empatia são pilares básicos para que essa relação tenha bons frutos. A afetividade foi apontada como primordial para alimentar essa relação complexa nos relatos apresentados pelas professoras.

Suas avaliações envolvem diferentes sujeitos, saberes e fazeres. A necessidade de classificar o aluno no que tange à sua aprendizagem está presente no processo por força institucional, mas não o domina. A avaliação é um movimento que tem recursos diversos, atrativos e intencionais para a efetivação do aprendizado de todos os envolvidos nesse processo.

Nesse sentido, nossa pesquisa confirma o que defende Roldão (2007) sobre a mediação e a dupla transitividade no processo de ensino-aprendizagem, uma vez que o grupo de 11 professoras investigadas demonstrou ensinar de um modo em que a transmissão do conhecimento faz parte do processo como uma das estratégias possíveis, mas não como o centro mobilizador do ensino. Para o grupo, o trabalho de mediação é determinante para a orientação e condução de um processo em que cada uma, enquanto docente, mobiliza saberes para que os seus alunos aprendam o conteúdo proposto de forma ativa e com sentido.

Defendemos ser de extrema importância que os professores sejam ouvidos, que narrem e apresentem suas experiências, que digam o que ensinam, como ensinam e por que ensinam desse jeito e não de outro, socializando suas concepções, seus saberes e fazeres. Assim, vão dando relevo à sua docência, à sua didática, à sua função de ensinar por meio de um saber que é teorizador, compósito e interpretativo, enquanto ação inteligente, que se funda em um domínio seguro de saber, que emerge de vários saberes formais e do saber experiencial, como construção de um processo de aprendizagem de outros e por outros, como defende Roldão (2007). Para essa autora, esse diferencial é o que continua a justificar, ou acentuar a necessidade da função dos professores como aqueles que se constituem como indispensáveis porque são os que fazem os outros aprenderem um saber que socialmente se considera necessário. 


\section{REFERÊNCIAS}

BARDIN, Laweance. Análise de Conteúdo. São Paulo: Edições 70, 2011.

BIERNACKI, Patrick \& WALDORF, Dan. Snowball Sampling: Problems and techniques of Chain Referral Sampling. Sociological Methods \& Research, vol.10 nº. 2, November, 141-163p, 1981.

DÍAZ BARRIGA, Ángel. Uma polêmica em relação ao exame. In: ESTEBAN, Maria Teresa (Org.). Avaliação: uma prática em busca de novos sentidos. Rio de Janeiro: DP\&A, 1999, p. 51-82.

GATTI, Bernardete. Formação de Professores no Brasil: características e problemas. Educação \& Sociedade, Campinas, v. 31, n. 113, p. 1.355-1.379, out./dez. 2010.

ROLDÃO, Maria do Céu. Profissionalidade Docente em Análise: especificidades dos ensinos superior e não superior. Nuances: Estudos sobre Educação, v. 12, nº. 13, Portugal, jan./ dez., p. 105-126, 2005.

ROLDÃO, Maria do Céu. Função docente: natureza e construção do conhecimento profissional. Revista Brasileira de Educação, v. 12, n. 34, 2007 [94-181].

ROLDÃO, Maria do Céu. Estratégias de Ensino: o saber e o agir do professor. Vila Nova de Gaia: Fundação Manuel Leão, 2009.

SHULMAN, Lee. Knowledge and teaching: foundations of the new reform. Harvard Educational Review, 57 (1), 1987, p. 1-22.

SHULMAN, Lee. Conocimiento y enseñanza: fundamentos de la nueva Reforma. Professorado: Revista de Currículum y formacion del professorado, v. 9, n. 2, p. 1, 2005.

TARDIF, Maurice. Saberes profissionais dos professores e conhecimentos universitários: elementos para uma epistemologia da prática profissional dos professores e suas consequências em relação à formação para o magistério. Revista Brasileira de Educação. jan./ fev./mar./abr., n. 13, 2000.

TARDIF, Maurice. Saberes docentes e formação profissional. Petrópolis, RJ: Vozes, 2002.

\section{DADOS DAS AUTORAS:}

\section{Rosineire SiLva de Almeida}

Mestre em Educação pelo Programa de Pós-Graduação em Educação da Universidade Federal do Rio de Janeiro. Rio de Janeiro/RJ-Brasil. rosineirealmeida@yahoo.com.br

\section{Giseli Barreto da Cruz}

Doutora em Educação. Professora do Programa de Pós-Graduação em Educação. Universidade Federal do Rio de Janeiro. Rio de Janeiro/RJ -Brasil. cruz.giseli@gmail.com

Submetido em: 27-12-2018

Aceito em: 25-11-2019 